\title{
Positive contrast spiral imaging of a nitinol guidewire
}

\author{
Adrienne E Campbell-Washburn ${ }^{1 *}$, Toby Rogers ${ }^{1}$, Burcu Basar ${ }^{1,2}$, Merdim Sonmez $^{1}$, Ozgur Kocaturk ${ }^{1,2}$, \\ Robert J Lederman', Michael Hansen', Anthony Z Faranesh'1 \\ From 18th Annual SCMR Scientific Sessions \\ Nice, France. 4-7 February 2015
}

\section{Background}

The clinical translation of MRI-guided cardiovascular catheterization has been limited by the unavailability of devices that are both visible and safe under MRI. In particular, rigid metallic guidewires are essential for most catheterization procedures and are at risk of heating during MR imaging [1]. Here we present an MRI method that simultaneously improves the visualization of commercially available nitinol guidewires and minimizes RF induced heating.

\section{Methods}

RF-efficient gradient echo spiral imaging was chosen to minimize heating ( 8 interleaves, TE $/ \mathrm{TR}=0.86 / 10 \mathrm{~ms}$, flip angle $\left.=10^{\circ}\right)$. Through-slice dephasing generated a positive contrast "device image" [2], exploiting local field inhomogeneity such that the metallic guidewire appears hyperintense with background signal suppressed. An anatomical image and a device image were interleaved in alternating frames. Image processing (signal thresholding and selection of elongated structures) was performed on the device image to isolate the guidewire signal from other sources of field inhomogeneity.

Imaging was performed on a 1.5T MRI scanner (Aera, Siemens, Erlangen, Germany). MRI-guided left heart catheterization was performed in a pig using a 0.035 " commercially available nitinol guidewire (Nitrex, Covidien, Plymouth, MN). The RF induced temperature rise at the tip of an insulated nitinol rod during MR imaging was measured in the ASTM 2182 gel phantom using a fiberoptic temperature probe (OpSense, Quebec, Canada).

\section{Results}

A pair of anatomical and device images were generated with a temporal resolution of $160 \mathrm{~ms}$ ( $80 \mathrm{~ms}$ per image), or 6.25 frames/s. Image processing occurred in real-time and a color overlay of the device on the anatomy was displayed to the operator for guidance during catheterization
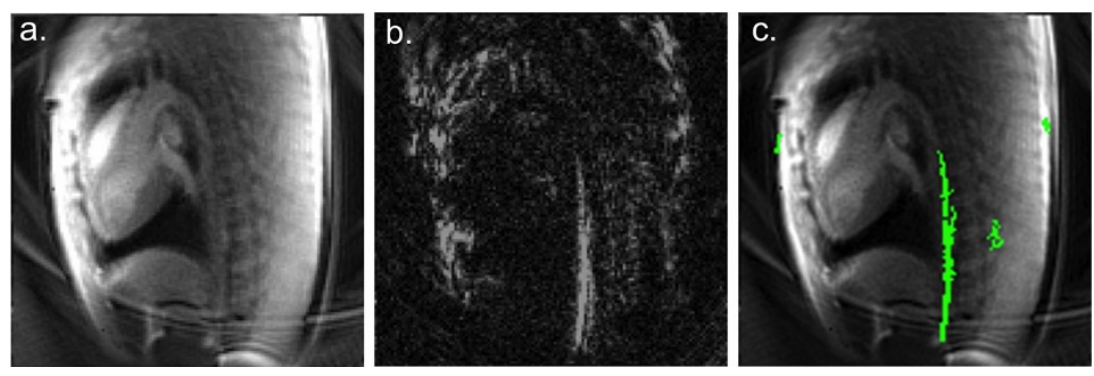

Figure 1 An example frame from MRl-guided left-heart catheterization in a pig using spiral imaging for interleaved anatomical images (a) and positive contrast device images (b). Real-time image processing was used to produce a color overlay of the guidewire on the anatomy for procedural guidance (c).

'Division of Intramural Research, Cardiovascular and Pulmonary Branch,

National Heart Lung and Blood Institute, National Institutes of Health,

Bethesda, MD, USA

Full list of author information is available at the end of the article

(c) 2015 Campbell-Washburn et al; licensee BioMed Central Ltd. This is an Open Access article distributed under the terms of the 

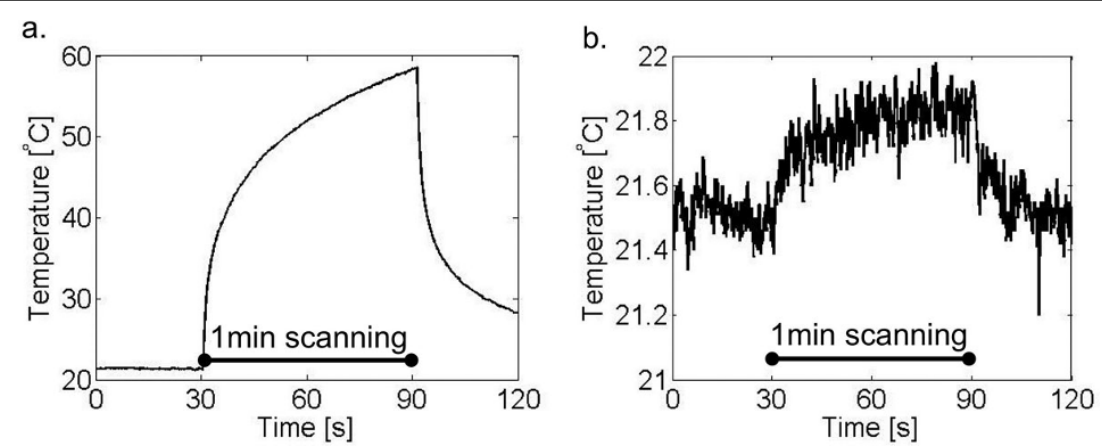

Figure $2 \mathrm{In}$ vitro temperature measurement at the tip of an insulated nitinol rod. Cartesian imaging (flip angle $=45^{\circ}, \mathrm{TE} / \mathrm{TR}=1.27 / 2.54 \mathrm{~ms}$ ) generated $37.2^{\circ} \mathrm{C}$ of heating (a) and spiral imaging (flip angle $=10^{\circ}, \mathrm{TE} / \mathrm{TR}=0.86 / 10 \mathrm{~ms}$ ) generated $0.47^{\circ} \mathrm{C}$ of heating (b) during 1 minute of continuous scanning.

(Figure 1). Isolation of the guidewire signal from the background was most challenging around the aortic arch.

During 1 minute of continuous scanning in vitro, our spiral imaging method generated $0.47^{\circ} \mathrm{C}$ at the tip of a nitinol rod, compared to $37.2^{\circ} \mathrm{C}$ of heating generated using standard Cartesian bSSFP imaging (Figure 2).

\section{Conclusions}

This method simultaneously improves guidewire visualization using a real-time color overlay and minimizes heating using RF-efficient imaging. Thus, this method may permit the safe and effective use of standard commercially available metallic guidewires for MRI-guided cardiovascular catheterizations.

\section{Funding}

This work was supported by the NHLBI DIR (Z01HL006039-01, Z01-HL005062-08).

\section{Authors' details}

'Division of Intramural Research, Cardiovascular and Pulmonary Branch, National Heart Lung and Blood Institute, National Institutes of Health, Bethesda, MD, USA. ${ }^{2}$ Institute of Biomedical Engineering, Bogazici University, Istanbul, Turkey.

Published: 3 February 2015

\section{References}

1. Konings MK, et al: Heating around intravascular guidewires by resonating RF waves. JMRI 2000, 12(1):79-85.

2. Seppenwoolde $J H$, et al: Passive Tracking Exploiting Local Signal Conservation: The White Marker Phenomenon. MRM 2003, 50:784-790.

doi:10.1186/1532-429X-17-S1-Q15

Cite this article as: Campbell-Washburn et al:: Positive contrast spiral imaging of a nitinol guidewire. Journal of Cardiovascular Magnetic Resonance 2015 17(Suppl 1):Q15.

\section{Submit your next manuscript to BioMed Central} and take full advantage of:

- Convenient online submission

- Thorough peer review

- No space constraints or color figure charges

- Immediate publication on acceptance

- Inclusion in PubMed, CAS, Scopus and Google Scholar

- Research which is freely available for redistribution

Submit your manuscript at www.biomedcentral.com/submit 